\title{
EFFECT OF A BASAL WATER LAYER ON THE DIMENSIONS OF ICE SHEETS
}

\author{
By J. WeERTMAN* \\ (U.S. Army Cold Regions Research and Engineering Laboratory, Hanover, New Hampshire, \\ U.S.A.)
}

\begin{abstract}
The effect of a basal water layer on the equilibrium dimensions of an ice sheet is examined. A thick water layer can decrease the equilibrium thickness of an ice sheet such as covers Antarctica (which contains no significant ablational areas) by a factor of the order of 2. Similar large changes in the equilibrium dimensions occur for ice-age ice sheets (which have extensive ablation areas). The extent of the ablation area of an ice-age ice sheet which may be covered with morainal debris is also calculated.

RÉsumÉ. Effet d'une couche d'eau basale sur les dimensions d'un indlandsis. L'effet d'une couche d'eau basale sur les dimensions d'équilibre d'un indlandsis est étudié. Une couche d'eau épaisse peut diminuer l'épaisseur d'équilibre d'un indlandsis tel que celui qui couvre l'Antarctique (qui ne possède pas de zones d'ablation significatives) par un facteur de l'ordre de 2. Des changements importants similaires des dimensions d'équilibre affectent les indlandsis des anciennes glaciations (possédant des zones d'ablation importantes). L'auteur calcule aussi l'extension de la zone d'ablation d'un ancien indlandsis pouvant ĉtre couverte par des débris morainiques.

Zusammenfassung. Einfluss einer Wasserschicht am Untergrund auf die Dimensionen von Eisschilden. Es wird der Einfluss einer Wasserschicht am Untergrund auf die Gleichgewichtsdimensionen eines Eisschildes untersucht. Eine dicke Wasserschicht kann die Gleichgewichtsdicke eines Eisschildes wie des antarktischen (der keine merklichen Ablationsgebiete enthält) um einen Faktor von der Grössenordnung 2 vermindern. Ähnlich grosse Änderungen in den Gleichgewichtsdimensionen kommen eiszeitlichen Eisschilden zu (die ausgedehnte Ablationsgebiete besitzen). Die Grösse des Ablationsgebietes eines eiszeitlichen Eisschildes, der mit Moränenschutt bedeckt sein kann, wird ebenfalls berechnet.
\end{abstract}

\section{INTRODUGTION}

This paper is an extension of a previous article (Weertman, I96 I [c]) which analyzed the stability of ice sheets. Since the $196 \mathrm{I}$ article was written there has been a new development relevant to ice sheet stability. It is the purpose of the present paper to incorporate this development into the analysis.

It now is clear that a water layer at the bottom of a glacier or an ice sheet may be able to influence profoundly the velocity at which the ice slides over its bed (Meier, I96o; Elliston [Union Géodésique et Géophysique Internationale], I963, p. 65-66; Paterson, r 964; Ostenso and others, I965; Friese-Greene and Pert, I965; Weertman, I962, I964; see, however, Meier, 1965). Therefore, an analysis of the stability of ice sheets must consider the effect of a basal water layer.

We also shall undertake a quantitative examination of a recent ice-age theory of Wilson (1964) which involves an extensive spreading out of the Antarctic Ice Sheet in a relatively short time period. This spreading is assumed to occur when the bottom surface of the ice sheet reaches the melting point. Wilson's theory is purely descriptive. Only by developing it quantitatively can its plausibility be established.

Finally, I wish to determine the extent to which the top surface of an ice-age ice sheet may be covered by morainal material. The stability of ice-age ice sheets obviously is affected by a widespread morainal cover.

Throughout this paper it will be assumed for the sake of simplicity that an ice sheet is uniform in cross-section and infinitely long in one direction. Thus, the ice sheet problems treated are two-dimensional ones. A further simplification will be made by developing the analysis using the perfect plasticity approach to glacier mechanics. This approach has one great advantage over the more nearly exact theory of glacier mechanics. Meaningful results

* Permanent address: Department of Materials Science and Department of Geology, Northwestern University, Evanston, Illinois, U.S.A. 
can be obtained without unduly complicated analyses. The next section will show how the more precise theory of glacier mechanics can be recast into the perfect plasticity theory.

Two varieties of ice sheets will be treated in this paper. One of these is the Antarctica type of ice sheet which contains no significant ablation areas. The other is the ice-age type of ice sheet, characterized by extensive ablation areas.

\section{Antarctica Type Ice Sheet}

An Antarctica type ice sheet contains no significant ablation areas. Its size is limited by the extent of its land base. The profile of such an ice sheet is found easily from a mass balance argument (Nye, I959; Weertman, I96r[a], I96r[c]). Suppose that the accumulation rate $a$ (given in equivalent of high-density ice) is constant. Between the center of an ice sheet and a point $x$ (see Figure $\mathrm{I}$ ) an amount of ice $a x$ is deposited in a unit time per unit length of ice sheet. If the ice sheet is in a steady-state condition, a like amount of ice must flow past the point $x$. The quantity $a x$ thus equals the product of the average ice velocity and the ice thickness.

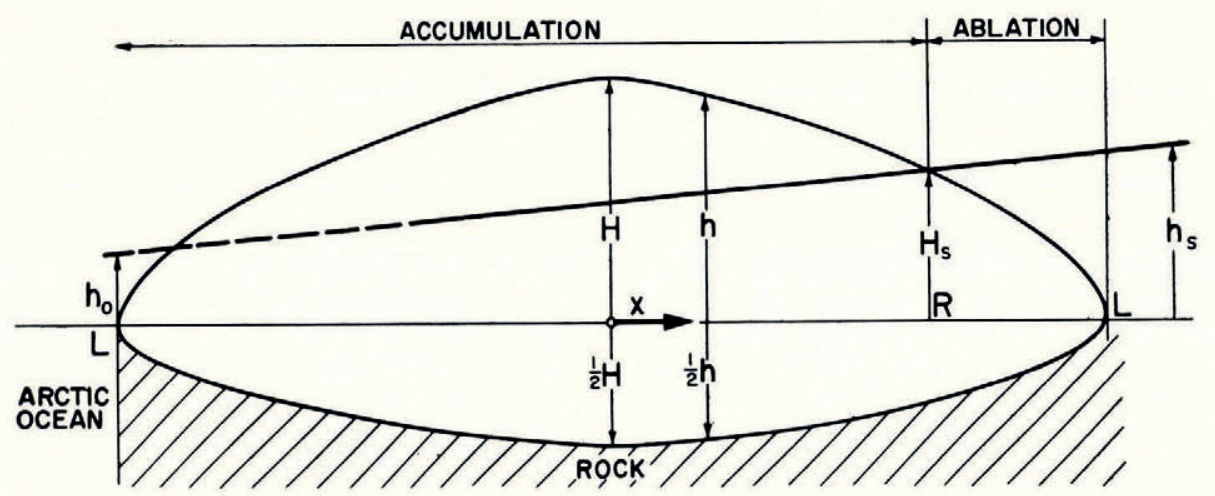

Fig. I. Cross-section of an ice-age ice sheet. The ice sheet is made into one of the Antarctica type by eliminating the ablation zone through setting $R=L$ and $H_{\mathrm{s}}=h_{0}=h_{\mathrm{s}}=o$

The ice sheet shown in Figure I rests on a land surface which originally was flat but now is depressed because of the weight of the ice sheet. The ice elevation above the original land surface is $h$ at point $x$. The lower surface is at a depth $\frac{1}{2} h$ below the original surface. This amount of isostatic depression occurs because the rock of the Earth's crust is approximately three times denser than ice.

Under steady-state conditions the average velocity $v$ of the ice at $x$ is given by

$$
v h=2 a x / 3 .
$$

The average ice velocity $v$ arises from creep deformation within the ice sheet as well as from sliding at the bottom. Both of these mechanisms lead to the following approximate equation (Nye, I959; Weertman, I96 I [a], I96r[c])

$$
v \cong B\left(\bar{\tau} / \tau_{0}\right)^{m}
$$

where $\bar{\tau}$ is the shear stress acting at the bottom, $m$ is a constant of the order of 2 to 3 , and $B$ and $\tau_{\mathrm{o}}$ are constants. If $\tau_{\mathrm{o}}$ is set equal to I bar, a reasonable value of $B$ is $8 \mathrm{o} \mathrm{m}$./yr. if (normal) sliding occurs and $40 \mathrm{~m}$./yr. if no sliding occurs and if the ice in the lower part of the ice sheet is within approximately $5^{\circ}$ to $10^{\circ} \mathrm{C}$. of the melting point.

Equations (I) and (2) can be combined in the following

$$
h^{(m+\mathrm{I}) / m} d h / d x=-(2 a x / 3 B)^{\mathrm{r} / m}\left(2 \tau_{\mathrm{o}} / 3 \rho g\right)
$$


since the shear stress $\bar{\tau}$ is equal to $3 \rho g h|d h / d x| / 2$. Integration leads to

$$
\left.\begin{array}{rl}
h^{(2 m+\mathrm{I}) / m} & =H^{(2 m+\mathrm{I}) / m}-\left(\frac{2 m+\mathrm{I}}{m+\mathrm{I}}\right)\left(\frac{2 \tau_{0}}{3 \rho g}\right)\left(\frac{2 a}{{ }^{B} B}\right)^{\mathrm{I} / m} x^{(m+\mathrm{I}) / m} \\
& =\left(\frac{2 m+\mathrm{I}}{m+\mathrm{I}}\right)\left(\frac{2 \tau_{0}}{3 \rho g}\right)\left(\frac{2 a}{3^{B}}\right)^{\mathrm{I} / m}\left\{L^{(m+\mathrm{I}) / m}-x^{(m+\mathrm{I}) / m}\right\}
\end{array}\right\}
$$

where ${ }_{3} H / 2$ is the total thickness of the ice sheet at its center and $L$ is the half-width of the ice sheet.

The profile of an ice sheet predicted by perfect plasticity theory is obtained by setting $m$ equal to infinity. This profile is

$$
h^{2}=H^{2}-(4 \tau / 3 \rho g) x=(4 \tau / 3 \rho g)(L-x)
$$

where $\tau$ has replaced $\tau_{0}$. In perfect plasticity theory $\tau$ is the stress level below which no plastic deformation can occur and above which an infinite amount occurs. The stress $\tau$ is the shear stress acting at the bottom of an ice sheet.

Equation (5) is a much simpler equation than (4). I would like to retain the simplicity of this equation and others analogous to it and yet, somehow, maintain the greater accuracy of equation (4). Both of these desires may be satisfied to a large extent by the compromise of using equation (5) and analogous equations but adjusting the value of $\tau$ so that both equations (4) and (5) give the same thickness at the center of an ice sheet.*

Thu;

$$
\tau=\tau_{0}\left(\frac{2 m+\mathrm{I}}{2 m+2}\right)\left[\left(\frac{2 m+2}{2 m+\mathrm{I}}\right)\left(\frac{\rho g L}{3 \tau_{0}}\right)\left(\frac{a}{B}\right)^{2}\right]^{1 /(2 m+\mathrm{I})}
$$

and

$$
H=\tau_{0}^{\frac{1}{2}} L^{\frac{1}{2}}\left(\frac{2 m+\mathrm{I}}{2 m+2}\right)^{\frac{1}{2}}\left[\left(\frac{2 m+2}{2 m+\mathrm{I}}\right)\left(\frac{\rho g L}{3 \tau_{0}}\right)\left(\frac{a}{B}\right)^{2}\right]^{\mathrm{I} /(4 m+2)} .
$$

Application to Wilson's ice-age theory: Wilson (1964) assumed that the Antarctic Ice Sheet will spread out rapidly (as a floating ice shelf) once its bottom surface reaches the melting point. His assumption is based on Robin's (I 955) theory of catastrophic glacier advances. When the bottom of an ice sheet previously frozen to its bed reaches the melting point and thus becomes able to slide, the effective value of $\tau$ decreases since $B$ increases $\uparrow$ roughly by a factor of 2. According to equations (5) and (6) the ice thickness $h$ diminishes by a factor of $\left(\frac{1}{2}\right)^{I /(2 m+I)} \cong \mathrm{I} / \mathrm{I} \cdot \mathrm{I} 23$, a $\mathrm{I} 2$ per cent decrease. In other words the effect of reaching the melting point is the same as would be obtained by perturbing the equilibrium thickness of the ice sheet by 12 per cent. A perturbation of this magnitude in the thickness of the Antarctic Ice Sheet would require a time period of the order of $5,000 \mathrm{yr}$. to be removed (Nye, I959). It hardly seems possible therefore that the Antarctic Ice Sheet will spread out rapidly into vast floating ice shelves as required by Wilson's theory if the ice sheet slides with normal sliding velocities.

Effect of a water layer: The sliding velocity of an ice sheet can be increased greatly if a water layer of appreciable thickness is present at the bottom. According to theory the sliding velocity increases by a large amount when the water layer thickness becomes comparable to, or larger than, the "controlling obstacle size" of sliding (Weertman, I962, r964). The

* Since $2 m+\mathrm{I} \cong 6$ the shear stress $\tau$ is roughly constant. Its dependence on $B$ will be taken into account throughout this paper. However its dependence on such quantities as accumulation rate will be ignored. It will become obvious how results such as are plotted in Figure 2 through 6 can be modified so as to take into account the dependence of $\tau$ on these other variables.

$\dagger$ This increase would occur if the temperature at the bottom surface changed from slightly below the freezing point to the freezing point. Larger changes in $B$ will occur if the temperature change is larger since the creep rate of ice increases by a factor of 2.5 for a temperature increase of $10^{\circ} \mathrm{C}$. (calculated using an activation energy of creep of 14,000 cal./mole). However, it is expected that a temperature rise at the bottom surface would occur gradually. The rapid change in $B$ that is required by Wilson's theory would only take place once the freezing point is reached. 
controlling obstacle size $\Lambda$ depends on the applied shear stress and is given by the equation

$$
\Lambda=C / \tau
$$

where $C$ is a constant. The constant $C$ depends on the roughness of the bed, being smaller the smoother is the bed. Therefore it is difficult to ascribe an exact value to $C$; its value ought to be of the order of $0.4 \mathrm{~cm}$. bar (Weertman, I964).

The thickness $D$ of the water layer is given by equation $(4 \mathrm{~A})$ of the Appendix:

$$
D \cong(\mathrm{I} 2 \mu U / \rho g|d h / d x|)^{\frac{1}{3}}
$$

where $\mu$ is the viscosity of water and $U$ is the volume of water in the water layer moving past $x$ in unit time, per unit length of the ice sheet. When only a negligible amount of heat is conducted down the temperature gradient within the ice sheet, the volume $U$ equals

$$
U=\int_{0}^{x}\left\{(Q+[S \tau / \mathcal{F}]) / H^{\star}\right\} d x
$$

where $Q$ is the geothermal heat, $S$ is the sliding velocity, $\mathcal{Z}$ is the mechanical equivalent of heat, and $H^{\star}$ is the latent heat of melting.

Under steady-state conditions $S_{\tau}=\beta \rho \operatorname{gax}|d h| d x \mid$, where $\beta$ is equal to $\frac{1}{2}$ if about one-half of the ice motion is due to sliding and is equal to $\mathrm{I}$ if almost all of the ice motion is due to sliding. Hence

$$
U=\left(Q x / H^{\star}\right)+\left(\beta \rho g a / \mathcal{J} H^{\star}\right)\left\{\int_{0}^{x} h d x-h x\right\} .
$$

If equation (5) is used to determine $h$, this equation reduces to

$$
U=\left(Q x / H^{\star}\right)+\left(2 \beta \rho g a / 3 \mathcal{F} H^{\star}\right)(4 \tau / 3 \rho g)^{\frac{1}{2}} L^{\frac{3}{2}}\left[\mathrm{I}-(\mathrm{I}-x / L)^{\frac{1}{2}}(\mathrm{I}+x / 2 L)\right]
$$

and the heat of sliding $Q_{\mathrm{s}}$ is

$$
Q_{\mathrm{s}}=S \tau / \mathcal{F}=\beta \tau a x / h \mathcal{F}=\beta a x(3 \tau \rho g / 4)^{\frac{1}{2}} / \mathcal{F}(L-x)^{\frac{1}{2}} .
$$

Equation (12) can be simplified if the mean value of $h$, which is equal to $2 H / 3$, is used in the expression for $Q_{s}$ :

$$
U \cong\left(Q x / H^{\star}\right)+\left(3 \beta \tau a x^{2} / \mathcal{J} H H^{\star}\right)
$$

According to theory (Weertman, I964), when the water layer thickness $D$ is equal to or larger than the controlling obstacle size $\Lambda$ the sliding velocity is one or more orders of magnitude larger than normal. The sliding velocity $S$ is given by

$$
S \cong\left(\operatorname{Io} B D \tau_{\circ} / C\right)\left(\tau / \tau_{0}\right)^{3} \text {. }
$$

Since this equation is of the same form as equation (2) the increase in the sliding velocity can be considered as caused by an increase in the effective value of $B$ in that equation. For an equilibrium ice sheet the effective value of the shear stress $\tau$ of perfect plasticity theory may be regarded as reduced when a thick water layer is present. In those regions where a thick water layer is present the effective shear stress $\tau^{\star}$ acting at the bottom can be obtained by combining equations (2), (6) and (15) and setting $2 m+\mathrm{I}=6$.

and

$$
\tau^{\star} \cong \tau\left(C / \mathrm{I} \circ D \tau_{\circ}\right)^{\frac{1}{3}} \quad \text { when } D \geqq \Lambda
$$

where $\tau$ is the value of the shear stress when the water layer is very thin. A combination of equations ( $16 \mathrm{a})$ and (9) leads to

$$
\tau^{\star}=\tau\left(C / \mathrm{IO} \tau_{0}\right)^{\frac{1}{3}}\left(\tau^{\star} / \mathrm{I} 2 \mu U h\right)^{\mathrm{I} / 9} .
$$

Since $\tau^{\star}$ depends on $U$ and $h$ only to a $\frac{1}{9}$ th power this stress is virtually independent of these variables. Therefore it is reasonable to approximate $\tau^{\star}$ by

$$
\tau^{\star}=\tau / M
$$


where $M$ is a constant greater than I. For $\tau=\tau_{\mathrm{o}}=\mathrm{I}$ bar, $D$ must be equal to or larger than $C / \tau$ when equation ( 16 a) is valid. Hence $M$ must be larger than (I0) ${ }^{\frac{1}{3}} \cong 2$. Another estimate of $M$ can be obtained from the velocity of catastrophic glacier advances if it is assumed that these rapid advances are indeed caused by a thick water layer (Weertman, 1962). The velocities of these advances are larger than normal velocities by a factor of 50 to 100 . Therefore $M$ should be of the order of $5^{0^{\frac{1}{3}}}$ to $100^{\frac{1}{3}}$ or approximately 4 . A reasonable estimate for $M$ is a value in the range from 2 to 4 .

Ice-sheet profile for thick water layer: Consider an ice sheet whose bottom surface everywhere is at the melting point. The water produced at the bottom flows outward and at a distance $\lambda$ from the center is of a sufficient thickness that $D \geqq \Lambda$. The ice sheet profile is found by setting $3 \rho g h|d h / d x| / 2$ equal to $\tau$ or to $\tau^{\star}$ and integrating. The profile is given by

$$
\left.\begin{array}{l}
h^{2}=H^{2}-(4 \tau / 3 \rho g) x \quad 0 \leqq x \leqq \lambda \\
h^{2}=H^{2}-(4 \tau / 3 M \rho g)(x+[M-\mathrm{I}] \lambda)=(4 \tau / 3 M \rho g)(L-x) \quad(x \geqq \lambda)
\end{array}\right\}
$$

where

$$
H=(4 \tau / 3 M \rho g)^{\frac{1}{2}}(L+[M-\mathrm{r}] \lambda)^{\frac{1}{2}}=\left(4 \tau_{\mathrm{av}} L / 3 \rho g\right)^{\frac{1}{2}} .
$$

Here $\tau_{\mathrm{av}}=L^{-\mathrm{I}}\left[\lambda \tau+(L-\lambda) \tau^{\star}\right]$ is the average value of the shear stress over the whole of the bottom of the ice sheet.

An approximate profile of the ice sheet can be obtained if it is assumed that the shear stress is constant everywhere and is equal to $\tau_{\text {av }}$. This profile is given by the equations:

$$
h^{2} \cong H^{2}-\left(4 \tau_{\mathrm{av}} / 3 \rho g\right) x=\left(4 \tau_{\mathrm{av}} / 3 \rho g\right)(L-x) .
$$

The distance $\lambda$ can be estimated by combining equations (8), (9) and (I4) and making the approximation that $\rho g|d h| d x \mid \cong 2 \tau / 3 H$. Thus

$$
\lambda=\left(C^{3} H^{\star} / 9 \tau^{2} \mu H Q\right) /\left\{\mathrm{I}+\left[\mathrm{I}+\left(2 \beta a C^{3} H^{\star} / 3 \mathcal{F} H^{2} Q^{2} \mu \tau\right)\right]^{\frac{1}{2}}\right\} .
$$

Should the geothermal heat be the predominant factor in equation (I4) this equation reduces to

$$
\lambda=C^{3} H^{\star} / 18 \tau^{2} \mu H Q .
$$

On the other hand if the heat of sliding predominates equation (19) reduces to

$$
\lambda=\left(C^{3} \mathcal{F} H^{\star} / 54 \mu \beta \tau^{3} a\right)^{\frac{1}{2}} .
$$

If in these equations $\lambda$ should turn out to be greater than $L$ of course the water layer does not affect the ice sheet. If $\lambda<L$ the ice thickness $H$ will vary between $\left(4 \tau / 3 M_{\rho g}\right)^{\frac{1}{2}}$ and $(4 \tau / 3 \rho g)^{\frac{1}{2}}$ as $\lambda$ varies between $o$ and $L$. Since $M \cong 2$ to 4 it can be seen that the presence of a water layer could reduce the equilibrium ice thickness by a factor of $I \cdot 4$ to 2 from the value it would have if the ice sheet were frozen to its base. A change of this magnitude is no longer a small perturbation and it could very well lead to the kind of catastrophic spreading of an ice sheet envisaged by Wilson in his ice-age theory. It should be strongly emphasized, however, that since the value of the constant $C$ appearing in the sliding velocity equations is not well known (and since the sliding theory itself is not yet established (or disproved) through experimental and field work) one cannot, at the present time, make a reliable prediction as to whether or not the catastrophic spreading of an ice sheet can occur.

It also should be emphasized strongly that even if catastrophic spreading takes place it still remains unlikely that the very extensive ice shelves which are required in Wilson's theory will be formed. A catastrophic spreading is likely to take place at velocities found in catastrophically advancing glaciers. These advance at speeds of the order of $10 \mathrm{~km}$. $/ \mathrm{yr}$. Hence it would require 50 to $100 \mathrm{yr}$. for the Antarctic Ice Sheet to spread. There appears to be no reason why the mechanisms which operate today to bound this ice sheet and its ice shelves to within continental limits cannot keep pace with an advance that occurs over such a long period of time.

The constant $C$ is determined by the degree of roughness of the bed of the ice sheet. If we 
choose the value of $C$ which is required to predict reasonable sliding velocities in glaciers $(C=0.4 \mathrm{~cm}$. bar) and if we take $\tau$ to be I bar, equation (20a) predicts that $\lambda=600 \mathrm{~km}$. Here we have used the values $\mu=5.7 \times 10^{-16}$ bar yr. $=0.018$ dyn. sec. $/ \mathrm{cm}^{2} ; H^{\star}=80$ cal. $/ \mathrm{cm} .{ }^{3} ; \mathcal{F}=4^{\mathrm{I}} \cdot 8 \mathrm{bar} \mathrm{cm} . / \mathrm{cal} . ; Q=40 \mathrm{cal} . / \mathrm{cm} .{ }^{2} \mathrm{yr}$.; and $H=2 \mathrm{~km}$. Equation (2ob) predicts that $\lambda=230 \mathrm{~km}$. if $\beta=\frac{2}{3}$ and $a=20 \mathrm{~cm}$. $/ \mathrm{yr}$., while equation (I9) gives $\lambda=190 \mathrm{~km}$. Since this last value of $\lambda$ is much smaller than $L$ for the Antarctic Ice Sheet the water layer effect obviously could be of great importance to this ice sheet. Consequently, that part of Wilson's ice-age theory which invokes a wide spreading of the Antarctic Ice Sheet cannot be dismissed lightly.

\section{Ice-Age Type Ige Sheet}

For an Antarctica type ice sheet variables such as the accumulation rate and the condition of the bottom surface influence only the thickness of the ice sheet and not its horizontal extent. In contrast an ice-age type ice sheet's horizontal dimensions, as well as its thickness, are a strong function of accumulation and ablation rates and of the elevation of its snow line (Weertman, I96 $[\mathrm{c}]$ ). For certain ranges of these variables an ice-age ice sheet cannot even exist. In this section I will extend the previous results to cover the situation in which a thick water layer exists at the ice-sheet bottom. The results will be developed using perfect plasticity theory rather than the more nearly exact theory used in my previous paper.

It can be shown* that the perfect plasticity approach gives a shear stress $\tau$ which is essentially the same as that calculated in the last section.

Consider now how the profile of the ice sheet of Figure I may be calculated. It is assumed that the right-hand (southern) side of this ice sheet has an accumulation area wherever the upper surface is higher than the snow-line elevation. The snow-line elevation $h_{\mathrm{s}}$ is given by

$$
h_{\mathrm{s}}=h_{\mathrm{o}}+s(L+x)
$$

where $s$ is the rate of rise of the snow line and $h_{0}$ is a constant. An ablation area occurs whenever the upper ice surface is beneath the snow-line elevation.

The left-hand (northern) side of the ice sheet is assumed to have no ablation area. The northern half of Figure $\mathrm{I}$ is of the Antarctica type and it loses its surplus accumulation through flow into the ocean.

In the accumulation areas the accumulation rate $a$ will be taken to be a constant; in the ablation areas the ablation rate $\bar{a}$ likewise is a constant. Both $a$ and $\bar{a}$ are positive quantities. Let $H_{\mathrm{s}}$ represent the elevation of the intersection of the upper surface with the snow-line elevation $h_{\mathrm{s}}$; let the elevation $h$ of the upper surface again be given by equation (5); let $x=R$ be the horizontal distance at which $h=h_{\mathrm{s}}$ (Fig. I). Thus

$$
H_{\mathrm{S}}=h_{\mathrm{o}}+s(L+R)=(4 \tau / 3 \rho g)^{\frac{1}{2}}(L-R)^{\frac{1}{2}} .
$$

* For example, consider a symmetric situation in which the snow-line elevation is given by $h_{\mathrm{s}}=s|x|$ for both the right and left hand sides of Figure $\mathrm{I}$. The ice-sheet profile obtained from the analysis that previously led to equation (4) now gives

where

$$
\begin{gathered}
H^{(2 m+\mathrm{I}) / m}=\left(\frac{2 m+\mathrm{I}}{m+\mathrm{I}}\right)\left(\frac{2 \tau_{0}}{3 \rho g}\right)\left(\frac{2 a}{3 B}\right)^{1 / m} L^{(m+\mathrm{I}) / m} \\
L=\left(\frac{\mathrm{I}}{s}\right)^{(2 m+\mathrm{I}) / m}\left(\frac{2 m+\mathrm{I}}{m+\mathrm{I}}\right)\left(\frac{2 \tau_{0}}{3 \rho g}\right)\left(\frac{2 a}{3 B}\right)^{1 / m}\left(\frac{a}{\bar{a}}\right)\left(\mathrm{I}+\frac{a}{\bar{a}}\right) .
\end{gathered}
$$

The effective stress $\tau$ corresponding to equation (6) now is

$$
\begin{aligned}
\tau & =\tau_{0}\left(\frac{2 m+\mathrm{I}}{m+\mathrm{I}}\right)\left[\left(\frac{2 m+2}{2 m+\mathrm{I}}\right)\left(\frac{\rho g L}{3^{\tau_{0}}}\right)\left(\begin{array}{c}
a \\
\ddot{B}
\end{array}\right)^{2}\left(\frac{\bar{a}}{a+\bar{a}}\right)^{2}\right]^{1 /(2 m+1)} \\
& =\tau_{0}\left(\frac{2 m+\mathrm{I}}{m+\mathrm{I}}\right)\left(\frac{2 a}{3^{s B}}\right)^{\mathrm{I} / m}\left(\frac{a}{a+\bar{a}}\right)^{1 /(2 m+\mathrm{I})}
\end{aligned}
$$


When the ice sheet of Figure $\mathrm{I}$ is in equilibrium the total ice accumulation $a R$ on its righthand side must equal the total ablation $\bar{a}(L-R)$. Hence

$$
R=\bar{a} L /(a+\bar{a}) .
$$

Combining the last two equations gives rise to the following equation for $L$ :

where

$$
L=\frac{1}{2} \lambda^{\prime}\left\{\mathrm{I}-\left(h_{\mathrm{o}}{ }^{\prime} / \lambda^{\prime}\right) \pm\left[\mathrm{I}-\left(2 h_{\mathrm{o}}{ }^{\prime} / \lambda^{\prime}\right]^{\frac{1}{2}}\right\}\right.
$$

and

$$
\begin{gathered}
\lambda^{\prime}=4 \tau a(a+\bar{a}) / 3 s^{2} \rho g(a+2 \bar{a})^{2} \\
h_{0}{ }^{\prime}=2 h_{0}(a+\bar{a}) / s(a+2 \bar{a}) .
\end{gathered}
$$

When $h_{0}$ is less than zero there is one solution of this equation for $L$ (with a positive value). When $h_{0}$ is greater than zero there is either no real solution for $L$ or there are two solutions. In the latter case it was shown previously (Weertman, I96 I [c]) that the larger value of $L$ represents a stable equilibrium ice sheet whereas the smaller value represents an unstable equilibrium ice sheet. By the terms "stable" and "unstable" is meant the following: If the value of $L$ were different than that given by equation (24) the right-hand side of the ice sheet would have a total budget surplus or deficiency. Therefore $L$ must change with time. Near a stable equilibrium value of $L$ the total budget is such that the ice sheet will shrink with time if the half-width is greater than the equilibrium value and it will grow if the half-width is smaller than the equilibrium value. The opposite behavior occurs when the ice sheet is near an unstable equilibrium value of $L$. It is impossible for a nonequilibrium ice sheet to adjust $L$ with time to the unstable equilibrium half-width.

If $h_{0}$ is equal to zero,

$$
L=4 \tau a(a+\bar{a}) / 3^{s^{2}} \rho g(a+2 \bar{a})^{2} .
$$

This value of $L$ represents the half-width of a stable equilibrium ice sheet.

When the radical of equation (24) is imaginary no real solution of $L$ exists. Therefore an ice-age ice sheet cannot exist whenever

$$
h_{0} s(a+2 \bar{a}) / a>\tau / 3 \rho g .
$$

Effect of water layer: The existence of a thick water layer under extensive regions of the bottom surface of an ice sheet causes a modification in the ice-sheet profile. Let the modified profile be given by the approximate equation ( $18 \mathrm{~b}$ ). The half-width $L$ of the ice sheet is given by equation (24), provided that $\tau_{\mathrm{av}}$ is substituted for $\tau$ in that equation. The average stress $\tau_{\mathrm{av}}$ is

if $L>\lambda$.

$$
\tau_{\mathrm{av}}=(\tau / L)(\lambda+[L-\lambda] / M)
$$

When $h_{0}=0$ and $\lambda \ll L$ the half-width $L$ is

$$
L=4 \tau a(a+\bar{a}) / 3 M s^{2} \rho g(a+2 \bar{a})^{2} .
$$

When this equation is compared with equation (25) it can be seen that the existence of a water layer reduces the equilibrium half-width by a factor of $M \cong 2$ to 4 .

The general solution for $L$ is found most easily by a graphical method. This method is illustrated in Figure 2. One curve in this figure is a plot of $\tau_{\mathrm{av}}$ versus $L$. The stress $\tau_{\mathrm{av}}$ is found from equation (27) using the values $\lambda=250 \mathrm{~km} ., M=4$, and $\tau=\mathrm{I}$ bar. The other curves are plots of $\tau$ versus $L$ obtained from equation (24). The curves are plotted using $h_{0}=300 \mathrm{~m}$. and $s=\mathrm{IO}^{-3}$ for various ratios of $\bar{a} / a$. Figure 3 shows a plot similar to Figure 2 except that various values of $h_{0}$ are employed for a constant ratio $\bar{a} \mid a=2$. The equilibrium widths are given (approximately) by the intersections of the sets of curves. For any one curve of $\tau$ versus $L$ the intersection with the smaller $L$ gives the unstable equilibrium half-width whereas the intersection with the larger $L$ is the stable equilibrium half-width. If there is no intersection the ice sheet cannot exist for those particular values of $h_{0}, s$ and $\bar{a} / a$. 


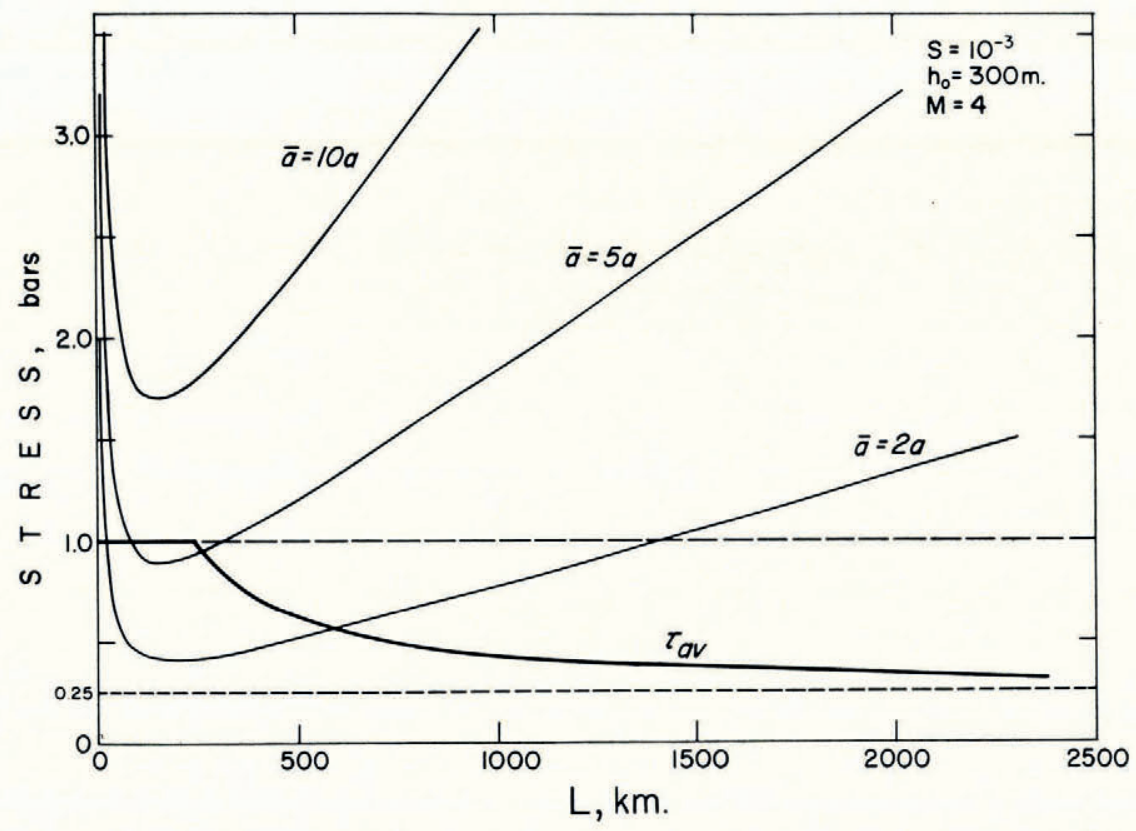

Fig. 2. Plots of $\tau$ versus $L$ given by equation (24) for various values of $\bar{a} / a$ and constant values of $h_{0}$ and $s$. Also plotted is $\tau_{\mathrm{av}}$ versus $L$ given by equation (27) for $\tau=I$ bar and $\lambda=250 \mathrm{~km}$.

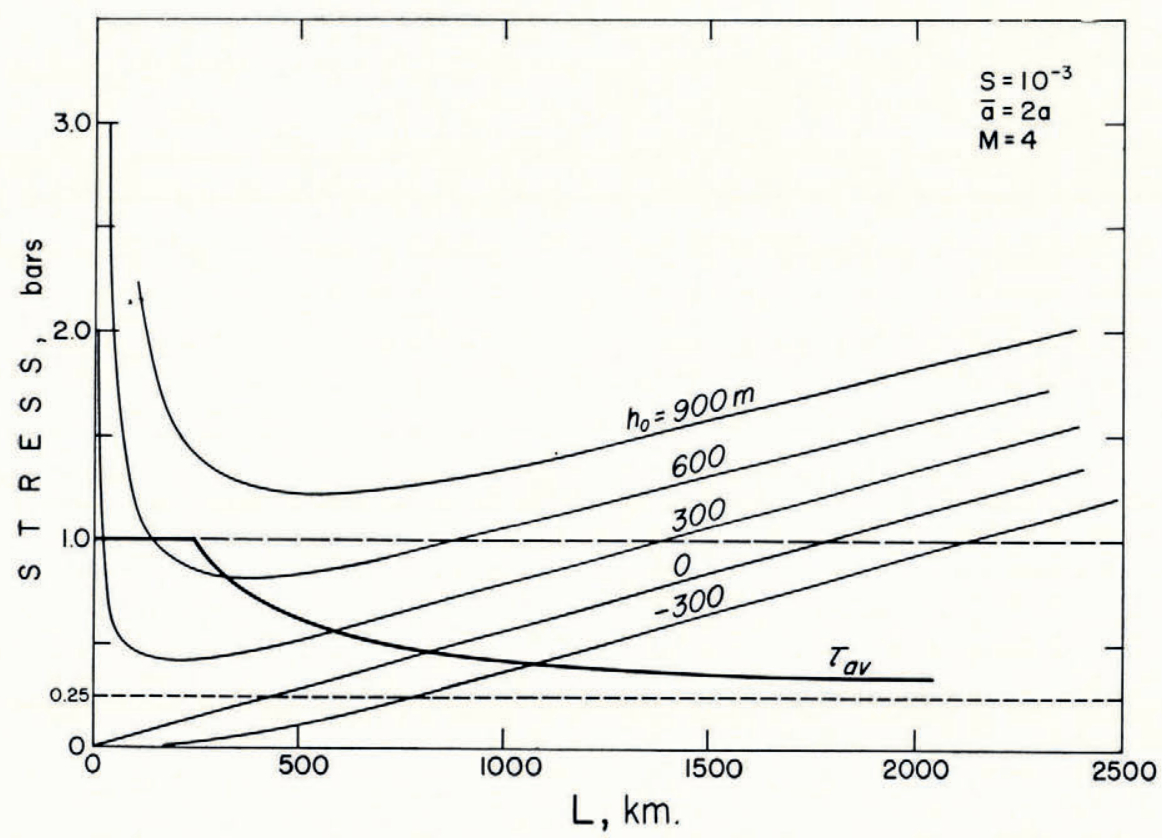

Fig. 3. Same plot as Figure 2 except that $h_{0}$ is varied instead of $\bar{a} / a$ 
When $\lambda \cong 0$ the inequality corresponding to inequality $(26)$ is

$$
h_{0} s(a+2 \bar{a}) / a>\tau / 3 M \rho g \text {. }
$$

If the inequality holds, an ice sheet with a thick water layer almost everywhere at its bottom surface cannot exist. Upon comparing inequalities (26) and (29) it is seen that the effect of the water layer is equivalent to reducing the accumulation rate or increasing the ablation rate or increasing $h_{0}$ or $s$ by a factor $M \cong 2$ to 4 . These are large equivalent changes in these quantities. It is clear that the presence or absence of a thick water layer at the bottom of an ice-age ice sheet is of extreme importance to the very existence of the ice sheet.

From plots such as Figures 2 and 3 it is possible to obtain curves of the half-width $L$ versus parameters such as $h_{0}$, etc. Figure 4 shows the relationship between $L$ and $h_{0}$ and Figure 5

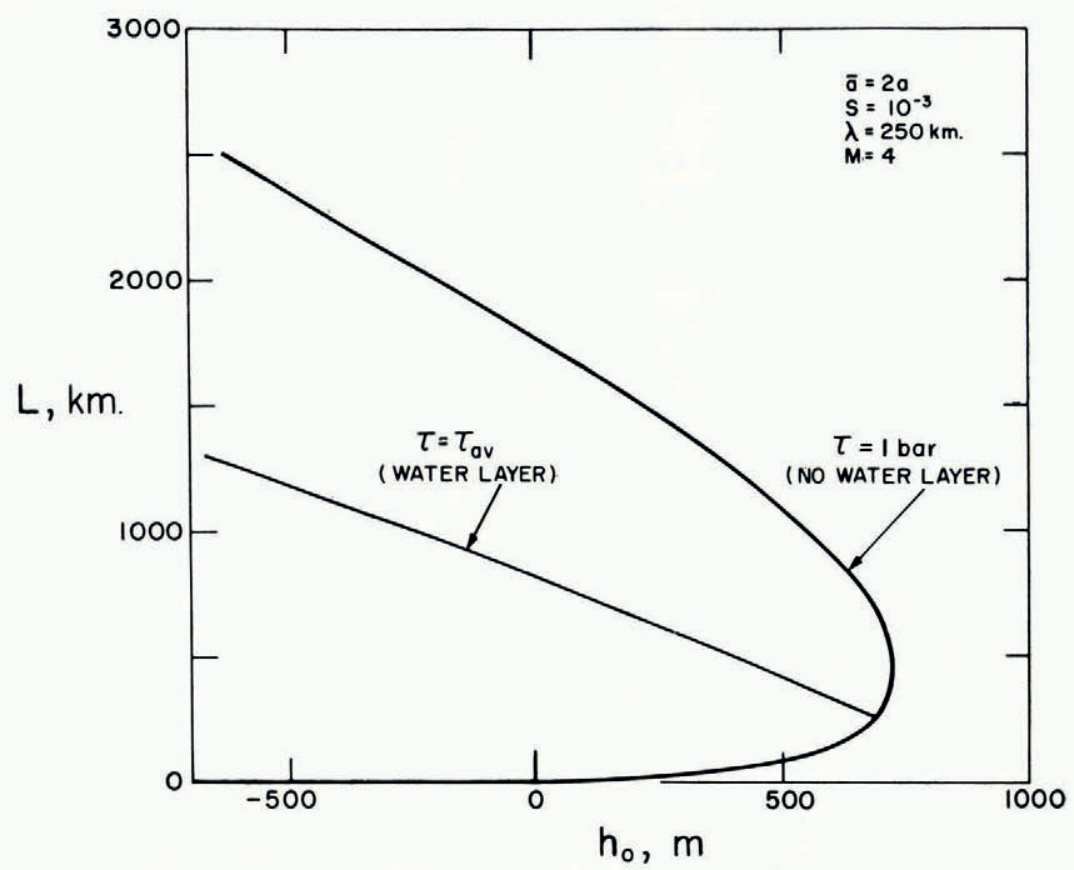

Fig. 4. Plot of half-width $L$ versus $h_{0}$ for constant values of $\bar{a} / a, s$ and $\lambda$

between $L$ and $\bar{a} / a$. In both figures the curves are drawn for the two cases of a thick water layer present and a thick water layer absent. It can be seen that in general the presence of the water layer causes the stable equilibrium half-width to decrease by a factor 2 .

Figures 6 and 7 show plots of $h_{0}$ versus $\bar{a} / a$ for constant values of the half-width $L$. The solid curves in these figures indicate the half-width for the case in which there is no thick water layer. The dashed curves give $L$ when there is a thick water layer beyond $x=\lambda=250 \mathrm{~km}$. No ice sheet can exist in the region above the heavy solid line; and no ice sheet whose bottom surface has a thick water layer everywhere (that is, $\lambda=0$ ) can exist in the region above the heavy dashed line in these two figures. The change in the half-width of an ice sheet when it reaches the melting point is found in Figures 6 and 7 from the intersections of the solid lines with the dashed lines. Again it can be seen that a water layer can lead to a large reduction in the equilibrium half-width.

Effect of a permeable bed: I have assumed so far that the bed of an ice sheet is impermeable to water. This is a reasonable assumption for major areas of the ice-age ice sheets of N.America, 
Europe and Asia. These ice sheets were centered on ancient crystalline shield areas whose rock is rather impermeable.

Suppose an ice sheet were to rest on a permeable (or fractured) rock bed of uniform thickness $D^{\star}$ which is underlaid by impermeable rock. Water will flow through this permeable layer. The amount of flow can be found by using Darcy's law. It states that the volume of fluid

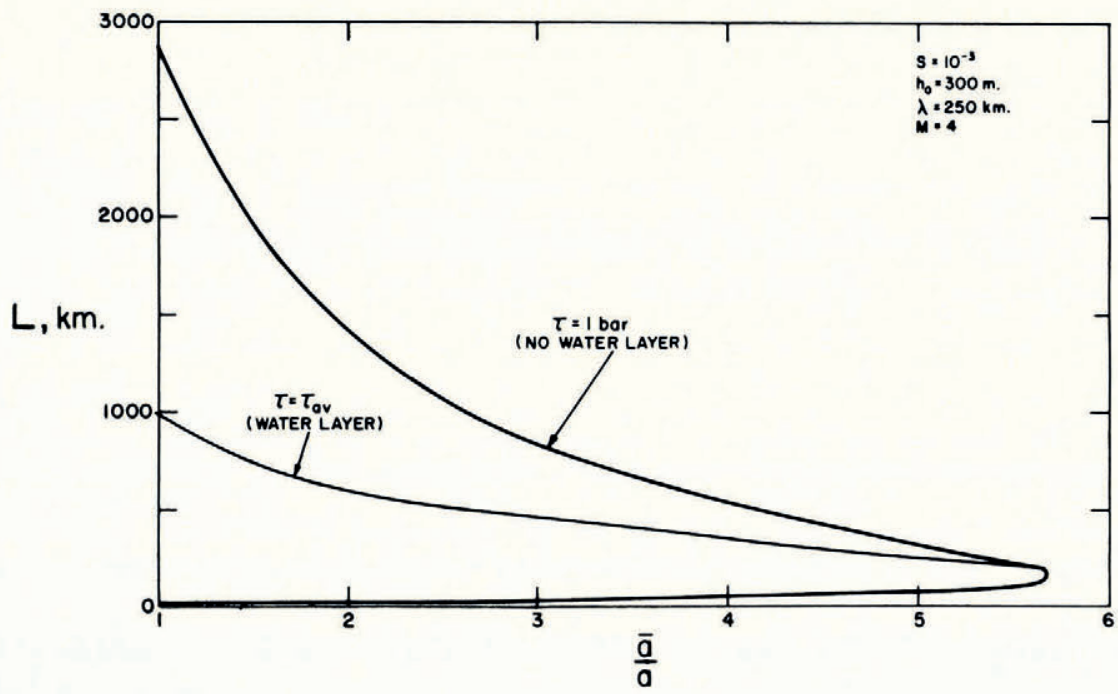

Fig. 5. Plot of half-width $L$ versus a $/ a$ for constant values of $h_{0}, s$ and $\lambda$

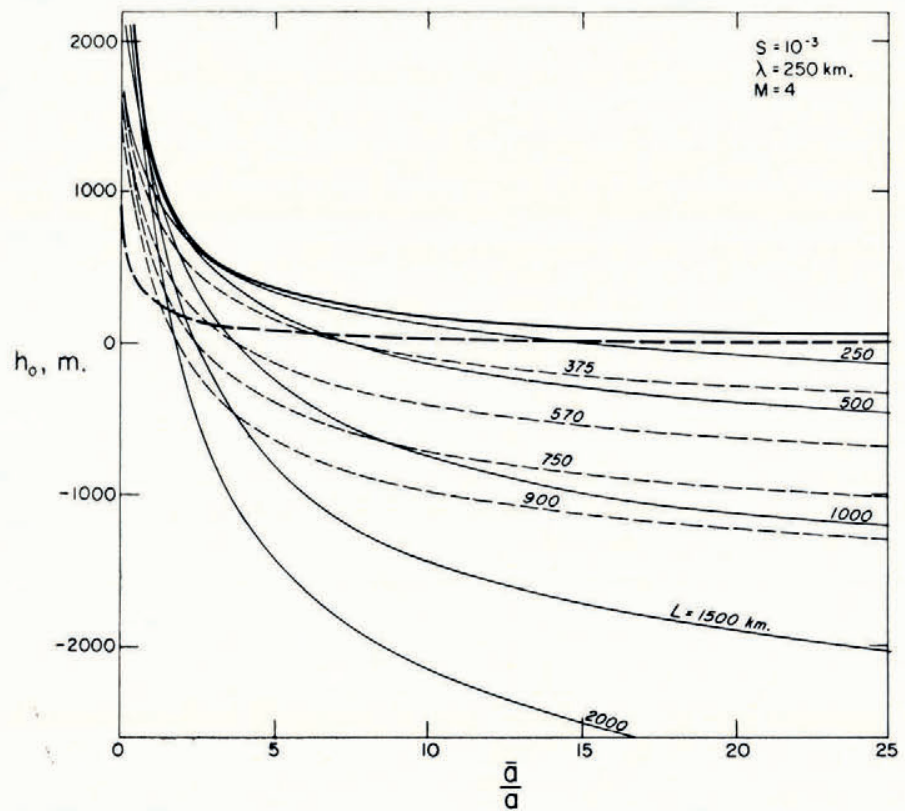

Fig. 6. Plot of $h_{0}$ versus $\bar{a} /$ a for constant values of $L$. The solid curves represent the case of a thin water layer and the dashed curves for a thick water layer 


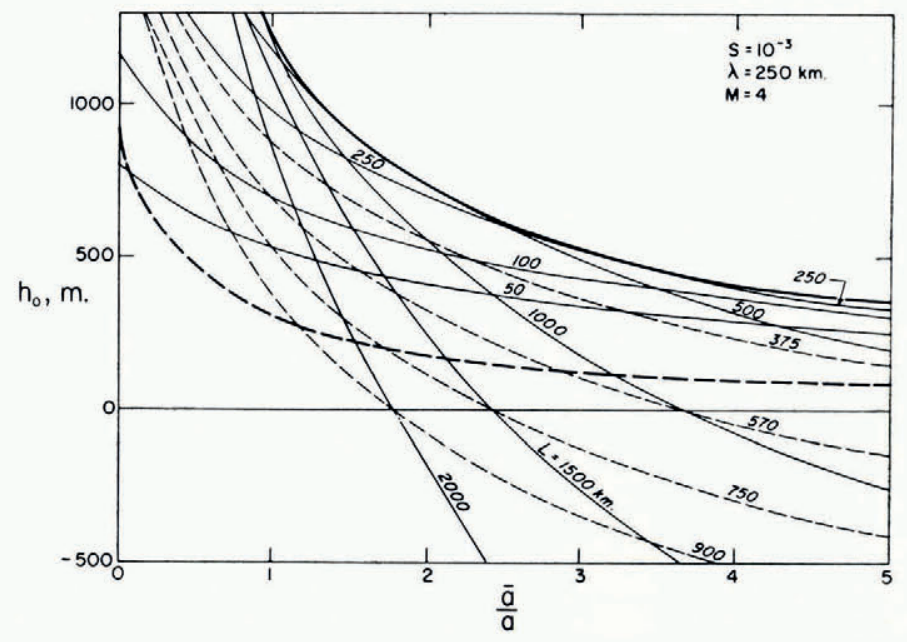

Fig. 7. Same plot as Figure 6 but on a different scale

flowing through a porous solid is proportional to the pressure gradient, the cross-sectional area and the inverse of the viscosity of the fluid. The constant of proportionality $K$ defines the permeability of the solid.

The water flow $U^{\star}$ through the permeable layer at an ice-sheet bed thus will be given by

$$
U^{\star}=K D^{\star} \rho g \alpha / \mu
$$

where $\mu$ is the viscosity of water and $\rho g \alpha \equiv \rho g|d h| d x \mid$ is the pressure gradient at the base of the ice sheet (see the Appendix). The volume of water flow $U$ in the water layer at the base is given by either equation $(3 \mathrm{~A})$ or $(9)$. It is

$$
U=D^{3} \rho g \alpha / 12 \mu
$$

where $D$ is the water-layer thickness. From a comparison of these last two equations it is seen that when

$$
D^{\star}<D^{3} / \mathrm{I} 2 K
$$

water flow in the basal water layer is more important than flow through the permeable zone. As an illustrative example, suppose that the permeable rock has a permeability of a typical oil sand. Thus $K \cong 0 \cdot \mathrm{I}$ Darcy $\cong \mathrm{IO}^{-7} \mathrm{~cm} \cdot{ }^{2}$ (Krumbein and Sloss, I963, p. I 20). If $D$ is greater than about $0.4 \mathrm{~cm}$. then $D^{\star}$ would have to be thicker than $0.5 \mathrm{~km}$. before the permeable zone could present a "short-circuiting" path for the water flow and thus prevent the water-layer effect from occurring. One may conclude that an ice sheet can rest on a fairly permeable and thick stratum without the occurrence of an appreciable decrease in the thickness of its basal water layer. Of course near the edge of an ice sheet where ice may rest on highly permeable, unconsolidated till a thick water layer is not expected to exist.

\section{Fraction of Ablation Area Covered by Morainal Material}

The rate of ablation of an ice-age ice sheet would be affected strongly by the amount of morainal material at its top surface and the extent of the area covered. Morainal material can be incorporated into an ice sheet through a freezing of melt water at the bottom surface (Weertman, I96r[b]). It is conceivable that the water layer of an ice sheet can affect its size and stability indirectly through this process. The following chain of events might occur. A small, unstable ice sheet may grow from a small to a large size with its bottom surface everywhere below the freezing point. The larger and thicker the ice sheet becomes the more 
probable is it that at the bottom of its central region the temperature will rise to the melting point (Robin, 1955). When this happens sliding occurs there. The geothermal heat and the heat of sliding melt ice from the bottom. (The geothermal heat $\cong 40 \mathrm{cal}$. $/ \mathrm{yr}$. can melt $\cong 0.5$ $\mathrm{cm} .^{2}$ per $\mathrm{cm} .3$ of ice per year. A sliding velocity of $80 \mathrm{~m}$. per year under a $\mathrm{I}$ bar shear stress can produce sufficient heat to melt about $3 \mathrm{~cm} .3$ of ice per $\mathrm{cm}^{2}$.) The water so produced flows towards the edge. The temperature gradient nearer the edge can be sufficiently large so that more heat can be conducted away than is produced by sliding or from the geothermal supply. In this region under these conditions water will freeze to the bottom of the ice sheet (Weertman, I96r[b]). Rock particles eroded from the bed and being pushed to the edge by the sliding motion will become frozen into the ice sheet. This process is illustrated in Figure 8. The thickness of the layer of "dirty" ice containing morainal material is calculated easily. Ice is melting at the bottom surface of the central region of the ice sheet of Figure 8 . The debris layer produced in the center by erosion must therefore be of insignificant thickness. The ice at the bottom surface in this region has a velocity component downwards and it is impossible to bring dirt and rock particles up into the ice mass.

Within the freezing zone of Figure 8 the ice at the bottom surface has a velocity component upwards. A thick layer of debris-filled, dirty ice can be created here. For simplicity suppose that the amount of water being frozen to the ice sheet per unit time and area in the freezing zone is a constant everywhere and is equal to $v^{\prime}$. Assume also that $v^{\prime}$ is much smaller than $a$ or $\bar{a}$.

The ice velocity in the vertical direction at the bottom surface must equal $(\partial y / \partial t)_{y=0}=v^{\prime}$ at the bottom surface, where $y$ is measured from the bottom surface. The vertical ice velocity when $y \neq 0$ is simply

$$
\partial y / \partial t=v^{\prime}-\dot{\epsilon} y
$$

where $\dot{\epsilon}$ is the longitudinal strain-rate. The strain-rate is approximately equal to the accumulation or ablation rate divided by the ice thickness for an equilibrium ice sheet. In the accumulation zone $\dot{\epsilon} \cong 2 a / 3 h$ and in the ablation zone $\dot{\epsilon} \cong-2 \bar{a} / 3 h$.

Integration of equation (33) yields the thickness of the debris-filled layer of dirty ice. It is necessary to know only the elevation of a piece of ice which originally is frozen to the ice sheet at $x=x^{\star}$, where $x^{\star}$ is the boundary position (Fig. 8) separating the regions where ice is melted from the ice sheet and water is frozen to the ice sheet. Let $y^{\prime}$ represent the elevation above the bed of the top of the debris layer of dirty ice. Let $S^{\prime}$ represent the horizontal velocity at $y=y^{\prime}$. Equation (33) can be rewritten as

$$
\partial y^{\prime} / \partial t=S^{\prime} \partial y^{\prime} / \partial x=v^{\prime}-\dot{\epsilon} y^{\prime} .
$$

Consider the left-hand side of the ice sheet of Figure 8. It contains only an accumulation

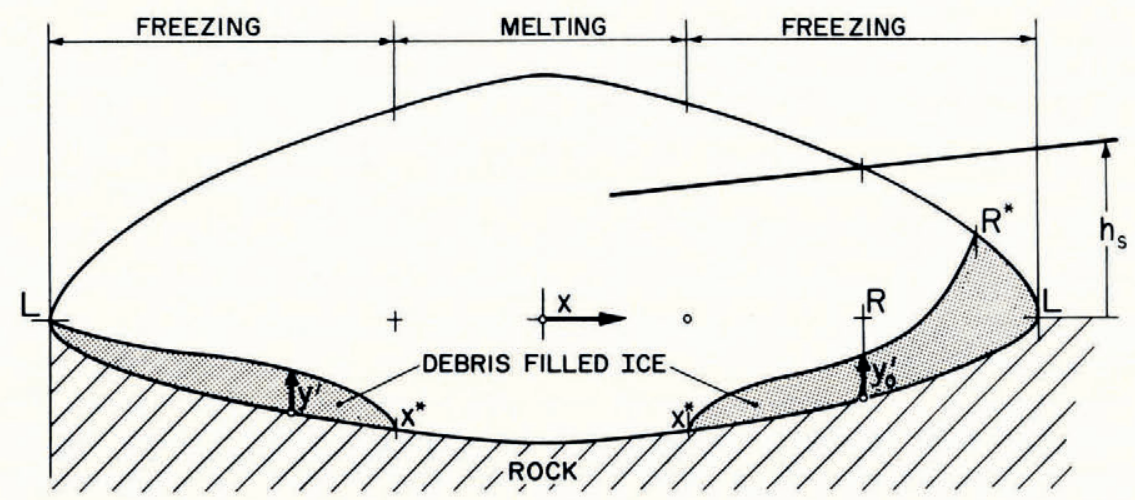

Fig. 8. Cross-section of an ice sheet containing morainal material 
area and hence the debris layer always is under an accumulation area. In this region $S^{\prime}=\gamma a x / 3 h=\gamma v$ where $v$ is the average ice velocity and $\gamma$ is the ratio of $S^{\prime}$ to $v$. The value of $\delta$ is approximately $\frac{1}{2}$ to $\mathrm{r}$. The distance $x$ is considered to be positive quantity. Equation (34) can be rewritten as

which has the solution

$$
\gamma d y^{\prime} \mid d x=\left(3 h v^{\prime} / 2 a x\right)-\left(y^{\prime} / x\right)
$$

$$
y^{\prime}=\left(3 h v^{\prime} / 2 a\right)\left[\mathrm{I}-\left(x^{\star} / x\right)^{\mathrm{I} / \gamma}\right]
$$

if $h$ and $\gamma$ are assumed to be roughly constant.

As $x$ increases the thickness of the ice layer containing morainal material reaches the value $3 h v^{\prime} / 2 a$. This thickness can be appreciable. For example, if $v^{\prime}=\mathrm{I}$ to $3 \mathrm{~cm}$. $/ \mathrm{yr}$., $a=20$ to $40 \mathrm{~cm}$. $/ \mathrm{yr}$., and $h=2,000$ meters, the thickness of the dirty ice layer $y^{\prime}$ is between 75 and $450 \mathrm{~m}$. This calculated thickness is of the same magnitude as the (presumed) morainal layer measured using seismic techniques in Antarctica (Bentley and Ostenso, 196r ; Behrendt, r963; Bentley, [ ${ }^{\mathrm{c}}{ }_{1964}$ ]) or measured directly through a bore hole in a thin portion of the ice sheet near its edge (Yevteyev, 1964 ). The theory leads, therefore, to reasonable results.

Consider next the thickness of the dirty ice layer in the right-hand side of Figure 8. Assume that $x^{\star}$ lies beneath the accumulation zone as shown. When $x^{\star} \leqq x \leqq R$ equations (35) and (36) are still valid. Beyond $x>R$ equation (35) is replaced with

$$
\gamma d y^{\prime} / d x=\left[\left(3 h v^{\prime} / 2 \bar{a}\right)+y^{\prime}\right] /(L-x)
$$

since $S^{\prime}=(2 \gamma / 3 h)[a R-\bar{a}(x-R)]=(2 \gamma \bar{a} / 3 h)(L-x)$. If $h$ and $\gamma$ are assumed again to be roughly constant the solution of this equation is

$$
y^{\prime}=\left[\left(3 h v^{\prime} / 2 \bar{a}\right)+y_{0}^{\prime}\right][(L-R) /(L-x)]^{\mathrm{x} / \gamma}-\left(3 h v^{\prime} / 2 \bar{a}\right)
$$

where $y_{0}^{\prime}$ is the thickness of the debris-filled layer at $x=R$. This last equation can be written in the form

$$
y^{\prime}=\left(3^{\prime} h v^{\prime} / 2 a\right)\left\{\left[(a / \bar{a})+\mathrm{I}-\left(x^{\star} / R\right)^{\mathrm{I} / \gamma}\right][(L-R) /(L-x)]^{\mathrm{I} / \gamma}-(a / \bar{a})\right\} .
$$

The layer of ice filled with morainal material reaches the upper surface at the point at which $y^{\prime}=3 h / 2$. Thus, the horizontal distance $x=R^{\star}$ at which this happens is approximately*

$$
L-R^{\star}=(L-R)\left\{\left[(a / \bar{a})+\mathrm{I}-\left(x^{\star} / R\right)^{\mathrm{I} / \gamma}\right] /\left[\left(2 a / 3 v^{\prime}\right)+(a / \bar{a})\right\}^{\gamma} .\right.
$$

If the start of the freezing zone lies under an ablation area $\left(x^{\star}>R\right)$ this last equation is replaced by

$$
L-R^{\star}=\left(L-x^{\star}\right) /\left[\left(2 \bar{a} / 3^{v^{\prime}}\right)+\mathrm{I}\right] .
$$

When $a / \bar{a}$ and $x^{\star} / R$ are small, the ratio of the area covered by morainal material to the total ablation area approximates

$$
\left(L-R^{\star}\right) /(L-R) \cong\left(3 v^{\prime} / 2 a\right)^{\gamma}
$$

The area covered by morainal material can be appreciable. For example, if $v^{\prime}=\mathrm{I}$ to 3 $\mathrm{cm}$. $/ \mathrm{yr}$., $a=20$ to $40 \mathrm{~cm}$. $/ \mathrm{yr}$., and $\gamma \cong \frac{1}{2}$ to $\mathrm{I}$, the ratio given by this last equation ranges from about 0.04 to 0.5 ( 4 to $5^{\circ}$ per cent).

\footnotetext{
* Another expression for the fraction of ablational area covered by morainic debris is found using a mass balance argument. Let $\bar{a}^{\star}$ represent the ablation rate in the region $R^{\star}<x \leqq L$ which is covered with morainal material and let $\bar{a}$ represent the ablation rate elsewhere. At equilibrium $a R=\bar{a}\left(R^{\star}-R\right)+\bar{a}^{\star}(L-R)$ if the amount of water escaping from beneath the ice sheet is negligible. The amount of ice $\bar{a}^{\star}\left(L-R^{\star}\right)$ which is melted in the morainal region $R^{\star}<x \leqq L$ must equal $v^{\prime}\left(L-x^{\star}\right)$. Combining these expressions gives

$$
\left(L-R^{\star}\right) /(L-R)=\left[\bar{a} v^{\prime}\left(L-x^{\star}\right) / \bar{a}^{\star}\right] /\left[a R+\left\{v^{\prime}\left(L-x^{\star}\right)\left(\bar{a}-\bar{a}^{\star}\right) / \bar{a}^{\star}\right\}\right] .
$$

When $\bar{a}^{\star} \ll \bar{a}$ the ratio $\left(L-R^{\star}\right) /(L-R) \approx \mathrm{I}$; when $\bar{a}^{\star} \gg \bar{a}$, $\left(L-R^{\star}\right) /(L-R) \approx \bar{a} v^{\prime}\left(L-x^{\star}\right) / a \bar{a}^{\star} R$; and when $\bar{a}^{\star}=\bar{a}$, $\left(L-R^{\star}\right) /(L-R)=v^{\prime}\left(L-x^{\star}\right) / a R$. The fraction of the ablation area covered with debris can range from $o$ to almost $r$.
} 
Even if $x^{\star}>R$ the ratio $\left(L-R^{\star}\right) /(L-R)$ can still be appreciable. In this situation equation $(39 \mathrm{~b})$ becomes

$$
\left(L-R^{\star}\right) /(L-R) \cong\left(3 v^{\prime} / 2 \bar{a}\right)^{\gamma}\left(L-x^{\star}\right) /(L-R) .
$$

For $v^{\prime}=\mathrm{I}$ to $3 \mathrm{~cm} . / \mathrm{yr}$., $\bar{a}=\frac{1}{2}$ to $2 \mathrm{~m}$. $/ \mathrm{yr}$., $\gamma \cong \frac{1}{2}$ to $\mathrm{I}$ and $\left(L-x^{\star}\right) /(L-R)=\frac{1}{2}$, this ratio lies between $0 \cdot 002$ to $0 \cdot 15(0 \cdot 2$ to 15 per cent $)$.

The results of this section show that it is possible to have an appreciable fraction of the ablation area covered by morainal debris if water is being frozen to the bottom surface of an ice sheet. A water layer can influence the size of an ice sheet indirectly through this freezing process.

\section{Discussion and Summary of Results}

The results of the analysis show that a water layer can have a profound effect on Antarctica and ice-age type ice sheets. When a thick water layer is present the average shear stress at the bottom of an equilibrium ice sheet must be smaller than normal. The reduced shear stress requires that the thickness of the ice sheet be reduced. For an ice-age type ice sheet the horizontal extent is reduced as well.

Unfortunately, it is not possible to obtain from the analysis a reliable estimate of the importance of the water-layer effect to the Antarctic Ice Sheet or the ice sheets that formerly covered parts of North America, Europe and Asia. The reason for this uncertainty is that quantities appearing in equations in the theory such as roughness of the bed are not well known. Moreover, the analysis is based on a sliding theory which awaits verification or disproof. At the present time it is not possible either to dismiss the water-layer effect or to accept the premise that it inevitably will produce, or has produced, large changes in the dimensions of ice sheets. In the future the uncertainty will be removed when field and experimental work lead to a firmer understanding of the sliding of glaciers and the effect of a water layer on this sliding.

Phenomenological arguments can be advanced in favor of the idea that a water layer is important to ice sheets. It seems certain now that the velocity fluctuations of glaciers arise from variations in the amount of surface melt water which reaches the bottom surface. The sudden, rapid advances (catastrophic advances) of some glaciers secms inexplicable except by some kind of water-layer effect. It is to be regretted that little field work has been done on rapidly advancing glaciers. An understanding of catastrophic advances is one of the more important problems remaining to be solved in glaciology. If glaciers exhibit phenomena such as rapid advances which may be produced by water layers, there is no reason why ice sheets may not show the same effect. In fact, from the equations developed in this paper it can be seen that if all other factors remain constant the larger is an ice sheet (or glacier) the more likely is the water-layer effect to become important.

The very fast velocity of the Jakobshavn Isbræ (Bauer, I96I) which drains part of the Greenland Ice Sheet (its maximum velocity, $\cong 5 \mathrm{~km}$. $/ \mathrm{yr}$., is of the same magnitude as those of catastrophically advancing glaciers) may be evidence that a water-layer effect is playing an important role at the present time in the mechanics of this ice sheet. Salinity studies of the seawater in the immediate vicinity of the end of this glacier presumably could establish whether or not there is an appreciable water flow at its base.

Should the water-layer effect be important the Antarctic Ice Sheet may very well go through the cycle pictured by Wilson ( 1964 ). In part of the cycle the ice sheet is frozen to its bed. In this stage the ice thickness builds up because the shear stress at the base is relatively high when the ice sheet is in equilibrium. The thicker the ice sheet becomes the more probable is it that the bottom surface will reach the melting point. If the water-layer effect occurs at this stage the ice sheet must reduce its thickness substantially in order to be in an equilibrium 
state. It does so by spreading out into floating ice shelves surrounding the Antarctic continent. The ice sheet then refreezes to the bottom surface because it is thinner.*

One might picture the following series of events in the history of ice-age ice sheets which involve the water-layer effect. A small ice cap such as one of those that exist in northern Canada today may become unstable and start to grow to a large size. (The ice cap is originally frozen to its bed and remains frozen as it grows.) When it becomes large its mere existence changes the world's climate and causes other ice sheets to grow in Europe and Asia. The increase in thickness of the ice sheet eventually leads to its bottom surface reaching the melting point. Through the water-layer effect the equilibrium size of the ice sheet is reduced. In time the ice sheet will shrink and approach the new equilibrium size. (The shrinking may be preceded temporarily by a spreading and thinning of the ice sheet similar to that proposed by Wilson for the Antarctic Ice Sheet.) It is possible that no equilibrium ice sheet can exist in which case the ice sheet will disappear. The reduction in size or disappearance of one ice-age ice sheet in the Northern Hemisphere would affect the world's climate and cause a change in size and the possible disappearance of the other ice sheets, thus ending the ice age.

It would be tempting to describe the ending of an ice age in the manner just outlined. It must be conditionally rejected, however, because it would lead to a nonsynchronous behavior of the ice-age ice sheets of North America and Europe during the end of the last ice age, whereas carbon dating evidence appears to indicate synchronous behavior. Although the existence of a thick water layer at the bottom of an ice-age ice sheet may not be a sufficient condition for ending an ice age it may be a necessary condition since it reduces significantly the change in the climate required to make the ice sheet disappear.

Another way in which a water layer may bring about changes in an ice sheet involves the morainal material brought up into the ablation area. This debris can increase the ablation rate if it occurs in only very small amounts or it can decrease the ablation rate if there is enough material to form a protective layer on the upper ice surface. Since the debris changes the albedo of an ice sheet it also may influence the climate and hence the size of the ice sheet. The presence of morainal material thus can cause both increases and decreases in the size of ice-age ice sheets. It is difficult to assess how important a role the morainal debris plays in the waxing and waning of ice-age ice sheets although obviously the effect can be large.

In these and previous (Weertman, ${ }_{96} \mathrm{I}[\mathrm{c}]$ ) considerations of the equilibrium size of ice sheets I am impressed with the fact that as far as the mechanics of ice sheets is concerned the main problem for ice-age ice theories to explain is not how an ice age starts but rather how it ends. ${ }^{\dagger}$ Ice caps of the size now existing in the Arctic do not require much change in their budget and in the snow line elevation in order to make them unstable and cause them to grow. Relatively trivial but long-term changes in climate whose origin may be beyond the ability of any theory to explain because of their small magnitude easily could lead to the large-scale growth of existing ice caps. It is much more difficult to make a large ice sheet disappear. If these ice sheets exist they are in stable equilibrium and a finite change in their accumulation or ablation rate or in the snow line elevation is required to produce the condition in which they cannot exist. The water layer effect can bring about the equivalent of this finite change in accumulation rate, etc., but unfortunately the synchronous behavior of the ice sheets during the end of the last ice age eliminates this effect as a mechanism for ending ice ages.

\section{MS. received 3 September 1965}

* Another strong objection to Wilson's ice-age theory can be raised regarding his requirement that the extensive floating ice shelves which are produced by the spreading of the ice sheet remain in existence to the close of an ice age. It is difficult to imagine how they could remain in existence for the long period between the start and the end of an ice age.

$\dagger$ Of course, the start of the first ice age of the Pleistocene is an important problem in itself. Once the earth has cooled sufficiently from whatever cause or the land level of the northern continents is raised to a high enough level to start the first ice age, the explanation of the start of succeeding ice ages becomes a secondary problem compared to explaining their endings. 


\section{REFERENCES}

Bauer, A. 196r. Influence de la dynamique des fleuves de glace sur celle de l'indlandsis du Groenland. Union Géodésique et Géophysique Internationale. Association Internationale d'Hydrologie Scientifique. Assémblee générale de Helsinki, 25-7-6-8 196o. Commission des Neiges et Glaces, p. 578-84.

Behrendt, J. C. 1963 . Seismic measurements on the ice sheet of the Antarctic Peninsula. Fournal of Geophysical Research, Vol. 68, No. 21, p. 5973-9o.

Bentley, C. R. [ $\left.{ }^{\mathrm{c}} \mathrm{I} 964\right]$ ]. The structure of Antarctica and its ice cover. (In Odishaw, H., ed. Research in geophysics. Vol. 2. Solid earth and interface phenomena. Cambridge, Mass., The M.I.T. Press, p. 335-89.)

Bentley, C. R., and Ostenso, N. A. 1961. Glacial and subglacial topography of West Antarctica. Fournal of Glaciology, Vol. 3 , No. 29, p. $882-9$ I 1 .

Friese-Greene, T. W., and Pert, G. J. 1965. Velocity fluctuations of the Bersækerbræ, East Greenland. Fournal of Glaciology, Vol. 5, No. 41, p. 739-47.

Krumbein, W. C., and Sloss, L. L. I963. Stratigraphy and sedimentation. Second edition. San Francisco, W. H. Freeman and Co.

Meier, M. F. 1960. Mode of flow of Saskatchewan Glacier, Alberta, Canada. U.S. Geological Survey. Professional Paper 35 $\mathrm{I}$.

Meier, M. F. 1965. Comments on Paterson's paper "Variations in velocity of Athabasca Glacier with time". Journal of Glaciology, Vol. 5, No. 41, p. $76 \mathrm{r}-62$.

Nye, J. F. 1959. The motion of ice sheets and glaciers. Journal of Glaciology, Vol. 3, No. 26, p. 493-507.

Ostenso, N. A., and others. 1965 . The bottom topography of Gulkana Glacier, Alaska Range, Alaska, by N. A. Ostenso, P. V. Sellmann and T. L. Péwé. Fournal of Glaciology, Vol. 5, No. 41, p. 651-60.

Paterson, W. S. B. 1964. Variations in velocity of Athabasca Glacier with time. Fournal of Glaciology, Vol. 5, No. 39 , p. $277-85$.

Robin, G. de Q. 1955. Ice movement and temperature distribution in glaciers and ice sheets. Journal of Glaciology, Vol. 2, No. 18, p. 523-32.

[Union Géodésique et Géophysique Internationale.] ig63. Colloque d'Obergurgl (suite). Bulletin de l'Association Internationale d'Hydrologie Scientifique, 8e An., No. 2, p. 50-142.

Weertman, J. ig6r [a]. Equilibrium profile of ice caps. Gournal of Glaciology, Vol. 3, No. 30, p. 953-64.

Weertman, J. I961 [b]. Mechanism for the formation of inner moraines found near the edge of cold ice caps and ice sheets. Fournal of Glaciology, Vol. 3 , No. 3o, p. 965-78.

Weertman, J. r96r[c]. Stability of ice-age ice sheets. Fournal of Geophysical Research, Vol. 66, No. 1 1, p. 3783-92.

Weertman, J. 1962. Catastrophic glacier advances. Union Géodésique et Géophysique Internationale. Association Internationale d'Hydrologie Scientifique. Commission des Neiges et Glaces. Colloque d'Obergurgl, IO-9-18-9 1962, p. $3^{1-39}$.

Weertman, J. 1964. The theory of glacier sliding. Fournal of Glaciology, Vol. 5, No. 39, p. $287-303$.

Wilson, A. T. r964. Origin of ice ages: an ice shelf theory for Pleistocene glaciation. Nature, Vol. 201, No. 4915, p. $147-49$.

Yevteyev, S. A. 1964. Determination of the amount of morainic material carried by glaciers of the East Antarctic coast. (In Soviet Antarctic Expedition. Information Bulletin. Vol. 2. Amsterdam, etc., Elsevier Publishing Co., p. 7-9.)

\section{APPENDIX}

\section{Water Flow at the Bottom of an Ice Mass}

In this appendix I will develop in more detail than I did previously (Weertman, 1962) the equations for governing water flow at the bottom of a glacier or an ice sheet.

The melt water produced by the geothermal heat and the frictional heat of sliding cannot accumulate in situ but must flow towards the edge of an ice mass. The force causing a small volume element of water to move is found as follows. Consider Figure 9. Shown here is a section of an ice mass of density $\rho$ whose upper surface is a

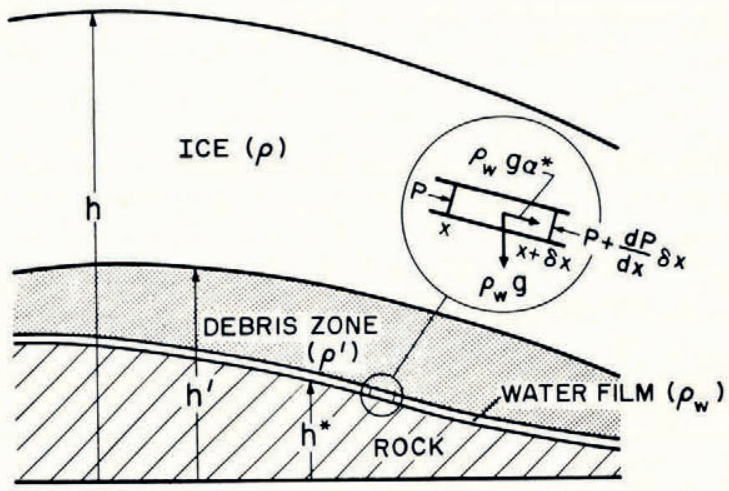

Fig. 9. Forces on an element of water in the water film at bottom of a glacier or ice sheet 
distance $h$ above a reference horizontal base line. The ice rests on an impermeable rock surface of elevation $h^{\star}$. A debris-filled ice zone of average density $\rho^{\prime}$ exists at the bottom of the ice mass. It extends to an elevation $h^{\prime}$ above the base reference line. It will be assumed that $|d h| d x||, d h^{\star}|d x|$, and $\left|d h^{\prime}\right| d x \mid$ are all small compared to $\mathrm{I}$. Here $x$ is horizontal distance towards the right in Figure 9 . For the moment it will be assumed that $h, h^{\star}$, and $h^{\prime}$ do not vary with the horizontal distance $z$ which is perpendicular to $x$.

The force per unit volume on a segment of the water film extending from $x$ to $x+\delta x$ is found with the aid of the insert of Figure 9. Gravity produces a downward force per unit volume of water of $\rho_{\mathrm{w}} g$, where $\rho_{\mathrm{w}}$ is the density of water and $g$ is the gravitational acceleration. This force has a component $\rho_{\mathrm{w}} g \alpha^{\star}$, where $\alpha^{\star}=\left|d h^{\star}\right| d x \mid$, in the direction parallel to the bed. The overburden pressure $P$ on the water layer at $x$ is equal to $\left[\rho\left(h-h^{\prime}\right)+\rho^{\prime}\left(h^{\prime}-h^{\star}\right)\right] g$. The gradient in pressure $d P / d x$ gives rise to a force per unit volume parallel to the bed equal to $\left[\rho\left(\alpha-\alpha^{\prime}\right)+\rho^{\prime}\left(\alpha^{\prime}-\alpha^{\star}\right)\right] g$, where $\alpha=|d h| d x \mid$ and $\alpha^{\prime}=\left|d h^{\prime}\right| d x \mid$.

The total force $F_{x}$ per unit volume on an element of water in the water film is

$$
F_{x}=g\left[\rho \alpha+\left(\rho^{\prime}-\rho\right) \alpha^{\prime}+\left(\rho_{\mathrm{w}}-\rho^{\prime}\right) \alpha^{\star}\right] .
$$

If the debris zone has a uniform thickness $\left(\alpha^{\prime}=\alpha^{\star}\right)$ or if its density is essentially that of ice $\left(\rho^{\prime}=\rho\right)$ the effect of this layer drops out of the equation, which reduces to

$$
F_{x}=g\left[\rho \alpha+\left(\rho_{\mathrm{w}}-\rho\right) \alpha^{\star}\right] .
$$

If $h, h^{\prime}$ and $h^{\star}$ of Figure 9 are functions of $z$ (the horizontal distance perpendicular to the plane of the figure) as well as $x$ an element of water will experience an additional component of force $F_{z}$ parallel to the bed but at right angles to that given by equation (1A). This force is given by

where

$$
F_{z}=g\left[\rho \beta+\left(\rho^{\prime}-\rho\right) \beta^{\prime}+\left(\rho_{\mathrm{w}}-\rho^{\prime}\right) \beta^{\star}\right]
$$

Since $\left(\rho_{\mathrm{w}}-\rho^{\prime}\right) / \rho \cong \frac{1}{10}$ and since $\left(\rho^{\prime}-\rho\right) / \rho$ also can be expected to be small, it can be seen that the slope of the upper ice surface determines predominantly the force on a volume element of water provided that $\alpha^{\star}$ and $\alpha$ are not an order of magnitude larger than $\alpha$ (or $\beta^{\star}$ and $\beta^{\prime}$ are larger than $\beta$ ).

The direction of flow of water at the base of a glacier or ice sheet thus is controlled largely by the slope of the upper surface rather than the slope of the bed. The upper surface slope will favour flow as a thin sheet of water. The slope of the bed will favor the flow of water in channels and streams.

The rate of flow of water in the water film under an applied force $F$ will be a function of this force as well as the thickness $D$ of the water layer and the viscosity $\mu$ of water. For the one-dimensional flow problem in which $F \cong \rho g \alpha$ the average velocity $V$ of water in the water film is (Weertman, 1962 )

This equation can be rewritten as

$$
\begin{aligned}
& V=D^{2} \rho g \alpha / \mathrm{I} 2 \mu . \\
& D=(\mathrm{I} 2 \mu U / \rho g \alpha)^{\frac{1}{3}}
\end{aligned}
$$

where $U=V D$ is the volume of water moving past $x$ per unit time and unit distance in the $z$ direction. 